\title{
LA MUERTE EN LA ARQUEOLOGÍA: VISIONES CRUZADAS / POSICIONES ENCONTRADAS
}

\author{
Death in Archaeology: Crossed Views / Oppsed Positions
}

\author{
Alejandra SÁNCHEZ POLO* \\ Universidad de Salamanca \\ E-mail: asanpol@usal.es
}

Fecha de recepción: 31-01-2010

Fecha de aceptación: 05-02-2010

\begin{abstract}
RESUMEN: La muerte, las necrópolis, los objetos enterrados junto a los difuntos constituyeron un reclamo para los primeros arqueólogos que con un indudable-pero ciertamente escaso- interés científico desenterraron estos preciados tesoros de innumerables yacimientos arqueológicos desde hace ya dos siglos. Progresivamente se ha ido abandonando esta posición anticuarista -sin duda, muy peligrosa para el desarrollo positivo de nuestra disciplinapara adoptar otros marcos de referencia que no primaran el objeto en sí mismo sino a la sociedad que lo produjo. En la presente comunicación se abordarán las posiciones teóricas que a lo largo del siglo XX han marcado hitos en la historiografía, tomando ejemplos de importantes yacimientos excavados, haciendo especial hincapié en cómo el interés científico de cada época se centra en aspectos específicos. Para finalizar, se realizará un avance de las posiciones más vanguardistas, exploradoras de horizontes que recalan en la racionalidad de las gentes del pasado.
\end{abstract}

Palabras Clave: Arqueología de la Muerte, Procesualismo, Post-procesualismo, Prehistoria, Península Ibérica.

ABSTRACT: Death, necropolis and the objects buried together with the deceased, represented an attraction to the first archaeologists that dug up -with little but an undoubted scientific interest- these valuable treasures in countless sites for two centuries. After words, this antiquarist vision of Archaeology has been abandoned to adopt other reference frames that did not take precedence over the object itself but also to the society which manufactured it. In the present communication, I will deal with theoretical 
positions that mark a historical milestone in the historiography along the XX century, taking samples from excavated sites, putting special emphasis on how scientific interest accent different aspects in each period. Finally, I will achieve a notice about the most vanguardist frameworks which explore the rational horizons of past people.

Key Words: Archaeology of Death; Functionalist Archaeology; Postprocessual archaeology; Prehistory, Iberian Peninsula.

En la presente comunicación se pretende abordar el fenómeno de la muerte grosso modo, con un breve resumen de las posiciones teóricas que han abordado esta temática desde los mismos inicios de la disciplina arquológica. Después nos centraremos en cómo han influido estos marcos de referencia en el caso concreto de la Edad del Bronce de la submeseta norte. Sin embargo, y a consecuencia de un registro arqueológico exiguo y de la incapacidad que éste genera para crear quórum, se propondrá, a partir de dos ejemplos -a vista de pájaro- sumamente diferentes tomados de la cuenca del Duero, una línea de investigación distinta.

\section{INTRODUCCIÓN}

La muerte es inherente a la naturaleza humana, un fenómeno excepcional que sin embargo, es cotidiano. Cada grupo social interpreta y se apropia este hecho, invistiéndolo de sacralidad en unos casos, en otros careciendo de ella (Ucko, 1969); afectando de manera diferente a la comunidad dependiendo de factores diversos, tales como la consideración de la muerte dentro de la misma, género, edad, grupo social o étnico del fallecido, circunstancias que rodearon la muerte del individuo, etc. (González-Tablas y Fano, 1994: 94-95). Precisamente por esta razón, la muerte es un hecho social, ya que los seres humanos racionalizamos y socializamos todo cuanto nos rodea. Asimismo, al igual que mueren las personas, no sería de extrañar que en algunas sociedades pudieran fenecer los objetos (Brück, 1999a), como luego se expondrá.

Tras un breve repaso al fenómeno de la muerte y aquello que constituye su reflejo inmediato como en las necrópolis, podemos afirmar que, desde el mismo momento en que dio comienzo la rebusca de objetos en la tierra y subsuelo con el fin de coleccionarlos y exhibirlos, fueron las tumbas las primeras en sufrir este afán de anticuarismo. Pasado el tiempo, ya a principios del siglo XX, y tras haber depurado objetivos, métodos y fines de las excavaciones arqueológicas ${ }^{1}$, comienza a ser constante la búsqueda de elementos de cultura material con el fin de establecer cronologías y dataciones. 
Es ahora cuando adquirieron importancia tanto los objetos en sí mismos como en relación al contexto en que se localizaron.

En pleno auge funcionalista (Chapman y Randsborg, 1981), aunque con el consabido retraso con respecto a otras partes del mundo, las inhumaciones de las gentes de la Prehistoria Reciente en la Península Ibérica fueron vistas a la luz de interpretaciones sobre las estructuras sociales y sus formas de organización como las propuestas en Antropología por Sahlins (1979). Se infería, por ejemplo, que a una mayor complejidad -como los túmulos megalíticos- y / o riqueza del enterramiento - las tumbas principescas del círculo argárico- correspondería un alto estatus, recreando positivamente la estructura social de los vivos a través de sus ritos fúnebres.

Avanzado el tiempo y ahondando en esta línea interpretativa, entraron en juego otras variables en la investigación de la cultura de El Argar²: la cuantificación - pareja a la vistosidad- de los ajuares, la amplitud de las viviendas donde eran enterrados o más recientemente, los análisis bioarqueológicos que se han realizados sobre los restos óseos han venido a refrendar la hipótesis de que El Argar estaba organizado mediante una estructura social fuertemente jerarquizada ${ }^{3}$.

Esta renovación teórica se efectuó en nuestro ámbito de estudio ${ }^{4}$ a partir del hallazgo de la sepultura de La Requejada (San Román de la Hornija, Valladolid) ${ }^{5}$ (Delibes, 1978). Por lo representativo de este trabajo, se utilizará como línea argumental para exponer la dinámica investigadora de estos años en los que la New Archaeology comenzaba a ser introducida en la Península Ibérica, aunque no completamente aceptada. A pesar de la ruptura más o menos significativa con respecto a la investigación precedente en cuanto a metodología de excavación, objetivos e incorporación de nuevas tecnologías, se seguían lastrando paradigmas historicistas mantenidos sin crítica alguna. Éstos estaban en directa relación con la estructura social de estas comunidades -tales como 'pastores de Cogotas I' (Delibes, 1978: 241)- o la sobrerrepresentación del estudio cerámico en su vertiente tipo-analógica en gran parte del trabajo (Ibidem: 231-244). También es cierto, que la aportación de este investigador destacó por quebrar las manidas teorías invasionistas que han primado hasta no hace mucho (Ibidem: 244) y por retrasar la cronología de la cerámica cogotense hasta el Bronce Final.

La arqueología de carácter funcionalista sigue desarrollándose en muchos de los centros de investigación peninsulares, al igual que se ha dado cabida a otras que priman aspectos positivistas, marxistas, sociales, de género, etc. Esta preponderancia de las tradicionales posiciones teóricas, ha fomentado que los campos de hoyos de la Prehistoria Reciente meseteña hayan intentado ser comprendidos como estructuras subterráneas cuyo último destino fue ser contenedores de los desperdicios cotidianos $s^{6}$ generados en poblados próximos de los que no quedan apenas huellas?. 
Además de estos y otros contenidos, los hoyos también sirvieron de sepulturas de algunos individuos de las comunidades cogotenses, aunque sin llegar a formar necrópolis o a tener distintivos externos ${ }^{8}$, como ocurre en otros contextos.

Continuando con los planteamientos teóricos que se han seguido para abordar el mundo funerario de la Edad del Bronce meseteña, la cuestión del rito cogotense fue revisada hace casi 20 años por Esparza (1990). Sin embargo, cabe afirmar que la síntesis realizada y las reflexiones que se planteaban ${ }^{9}$ siguen sin superarse a pesar de no ser completamente satisfactorias, como señalaron oportunamente algunas voces críticas. Éstas pusieron especial énfasis en reconocer el carácter excepcional de las inhumaciones cogotenses, así como de otros restos humanos que también aparecen en las excavaciones mezclados entre el material de desecho, destacando, además, la singularidad de cada tumba, puesto que resulta difícil encontrar rasgos homogeneizadores más allá del hecho de haber sido depositados en hoyos (Díaz-del-Río, 2001: 148-154; González-Tablas y Fano, 1994: 98-101).

La falta de unanimidad, anima a plantear un nuevo enfoque integrador para comprender las razones de excavación y colmatación de estos hoyos durante la Prehistoria Reciente, más allá de una compresión parcelaria según su función primigenia o secundaria, por otro lado nada excepcional en la investigación de este grupo arqueológico.

\section{LA MUERTE DE UN INDIVIDUO: EL CASO DE CARRELASVEGAS}

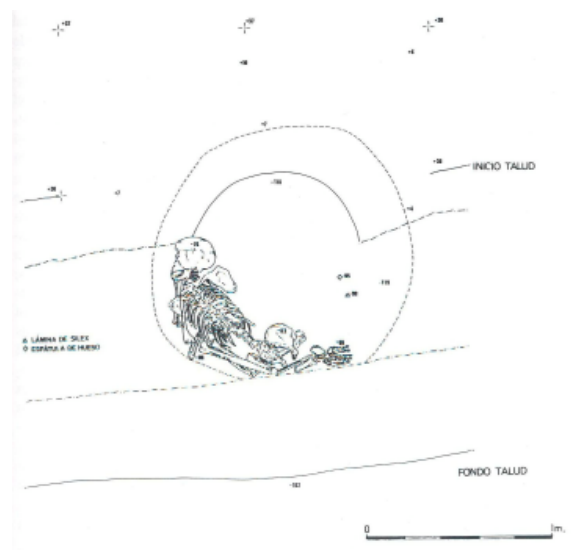

Fig. 1: Inhumación de Carrelasvegas (Santillana de Campos, Palencia) (Martín Carbajo et al., 1993: 77; fig. 6). 
Hallazgos como el del yacimiento de Carrelasvegas (Santillana de Campos, Palencia) (Martín Carbajo et al., 1993) ejemplifican esta nueva vía de aproximación, puesto que además de documentarse un depósito mortuorio peculiar, otras fosas tenían en su relleno materiales significativos que desafían valores del sistema lógico occidental como la maximización del coste de producción mediante la amortización total del objeto (Brück, 1999a: 313-314).

Así, un hoyo singular en cuanto a material arqueológico, tenía en su base un molino de granito y en un punto indeterminado del relleno, un colgante con escotaduras (Strato, 1991: 28). Otra subestructura, sellada con tierras estériles, contaba con un nivel inferior de arenas negras y dos cerámicas prácticamente completas (Martín Carbajo et al., 1993: 71). Por último, hay que destacar la aparición de dos hoyos secantes, el más antiguo de los cuales, además de restos óseos y fragmentos cerámicos contenía una placa rectangular procedente de un hogar y adobes, y en cambio, el más moderno, además de tener sus paredes revocadas, estaba sellado por una capa de tierra rojiza, resultando extraño el escaso lote de restos materiales recogidos (Strato, 1991: 22-23).

Así mismo, en este yacimiento se documentó una inhumación individual en un hoyo, el D-1 (Fig. 1), que no destacaría a simple vista entre los otros 9 excavados: similares medidas, relleno parecido en cuanto a coloración y composición, etc. Sin embargo, sobre la base del hoyo D-1 se registró al W un nivel de tierra quemada mezclada con fragmentos cerámicos de gran tamaño, mientras que en el nivel superior nos encontramos el esqueleto de un hombre ${ }^{10}$ arrinconado contra la pared $\mathrm{S}$ del hoyo. Como posible ajuar podría entenderse la lámina de sílex y la espátula de hueso que se hallaban en el E, algo que resulta extraño en el 'Rito Funerario de Cogotas I' (González-Tablas y Fano, 1994: 98). Otros restos humanos que contenía la sepultura eran dos costillas a los pies del anterior difunto, a una cota inferior, una clavícula y una calota craneal al N del hoyo (Martín Carbajo et al., 1993: 78-79).

Para paliar la extrañeza que causa esta inhumación, los autores del estudio recogen propuestas anteriores sobre la hipotética reutilización de un hoyo en proceso de colmatación o la posibilidad de que con vistas a la invisibilización del carácter funerario del mismo se trajera tierra procedente de otro lugar con enterramientos más antiguos -de ahí que se localizasen restos inconexos de otro individuo-, o incluso que el aparente polimorfismo funerario de este grupo cultural se debiera a condicionantes de tipo geográfico, y ante todo, de tradiciones ancestrales profundamente arraigadas (Ibidem: 82), como ya apuntara Esparza (1990: 134-136).

Habría que resaltar otros aspectos que parecen haber sido olvidados, y es que este depósito estaba 'estructurado' (Hill, 1995). Antes de introducir el cadáver y arrinconarlo contra la pared, el hoyo ya había sido escenario de 
otros actos que de ninguna manera habrían sido arbitrarios, sino planificados y organizados en la siguiente secuencia: elección -o excavación- de una cubeta de dimensiones considerables ${ }^{11}$; realización de un fuego, si es que no se trata de los restos de un hogar traídos ex profeso; deposición de algunos restos humanos inconexos -fragmentos de calota, clavícula y dos costillas- correspondientes al menos a un individuo; por encima, inhumación de un individuo completo, arrinconado -como es frecuente en Cogotas I- contra la pared del hoyo y colocado en un llamativo decúbito prono; finalmente, colocación de la espátula de hueso y la lámina de sílex en una zona vacía, claramente separada del inhumado.

Por tanto, ¿Podemos seguir afirmando la aleatoriedad del hecho mortuorio cogotense? ¿Cómo podemos entender un contexto arqueológico tan complejo como el aquí descrito?

En definitiva, a la vista de la documentación obtenida en este campo de hoyos, hay que reconocer que no podemos sino desechar el prejuicio de monotonía y homogeneidad que parece presidir la excavación y estudio de los campos de hoyos en general (Fernández-Posse, 1998: 114). Cada depósito es diferente -uno con restos de al menos dos cadáveres, otro con dos elementos de vajilla cerámica casi completos, otro con un colgante y un molino todavía útiles, otro con restos de lo que parece la limpieza de una cabaña- y podría responder a inquietudes muy diversas. Tenemos en este yacimiento, por tanto, materiales que cabría interpretar como restos de una compleja ocupación humana con todos los elementos de un poblado, incluyendo quizás a algunos de quienes lo habitaron. Por esta razón resulta inquietante y desconcertante a un tiempo que las cabañas no estén presentes y sin embargo, haya constancia de que una parte del material localizado no hubiese terminado su ciclo vital en el momento de colmatación de las estructuras.

En sintonía con las interpretaciones habituales sobre la permanente movilidad de unas comunidades seminómadas, pudiera sugerirse que algunos de estos vestigios -los más pesados, por ejemplo- hubieran sido ocultados para cuando, más adelante, se produjera el regreso a un poblado que se abandonó temporalmente. Pero el conjunto de los datos parece invitar a buscar explicaciones más complejas.

Hoyos de POSTE Y PELLAS DE BARRO: EL PULSO DÉBIL DE LAS ESTRUCTURAS DE HABITACIÓN

Si los enterrados -humanos o no- reclaman una mayor atención, por idénticas razones habrá que volver también sobre la pista de las viviendas. Si fueron borradas de manera sistemática de los yacimientos, quizá no se debió únicamente a procesos postdeposicionales, bien erosivos -riadas, por ejem- 


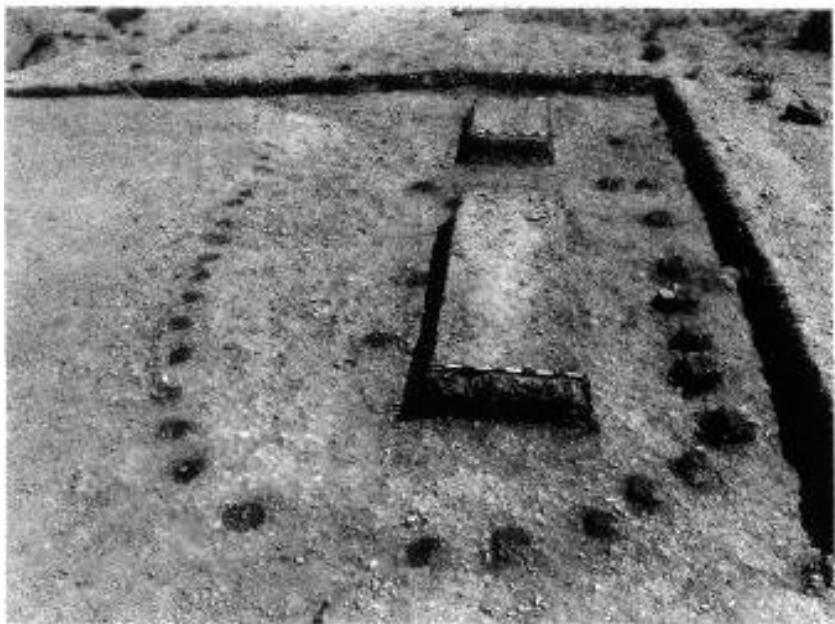

Fig. 2: Hoyos de poste de la cabaña del Teso del Cuerno (Forfoleda, Salamanca) (Martín Benito y Jiménez, 1988-9: 280; fig. 2).

plo- o bien antrópicos, en relación con la actividad agrícola (Martín Benito y Jiménez, 1988-9: 267; Sanz García et al., 1994: 76), sino a acciones deliberadas, a decisiones conscientes ${ }^{12}$ cuyo significado, por el momento, no podemos llegar a comprender.

A pesar del carácter efímero ${ }^{13}$ de la estructura aérea de las casas o de los hoyos de poste, que con frecuencia se localizan aislados y confundidos en los campos de hoyos, se han conservado numerosos -aunque escasos en conjunto- ejemplos probablemente indicativos de lo que se podría registrar en otros muchos yacimientos, y que sin embargo, se encuentran en estado fragmentario en las subestructuras. Viviendas como la del Teso del Cuerno (Forfoleda, Salamanca) (Martín Benito y Jiménez, 1988-9: 266) o el Sector A de los Tolmos de Caracena (Soria) (Jimeno y Fernández Moreno, 1991: 1516) son los testimonios, inusitados y pobres, de la vida de las personas que excavaron y rellenaron miles de hoyos.

La primera (Fig. 2) tiene insinuado su trazado elíptico mediante 33 hoyos de poste, que se completan con 4 más en el interior de la vivienda. Las medidas de ésta son $4 \mathrm{~m}$. de anchura y $9 \mathrm{~m}$. de longitud máxima, estando el área interior recubierta por un suelo compacto (Martín Benito y Jiménez González, 1988-9: 266). En este yacimiento tampoco faltan restos de manteado de barro en 20 de los hoyos documentados (González González, 1994: 312).

En el yacimiento soriano (Fig. 3), por su parte, se documentaron -bajo unos $25 \mathrm{~cm}$. de tierra negra que presentaba abundantes carbones y pellas de 


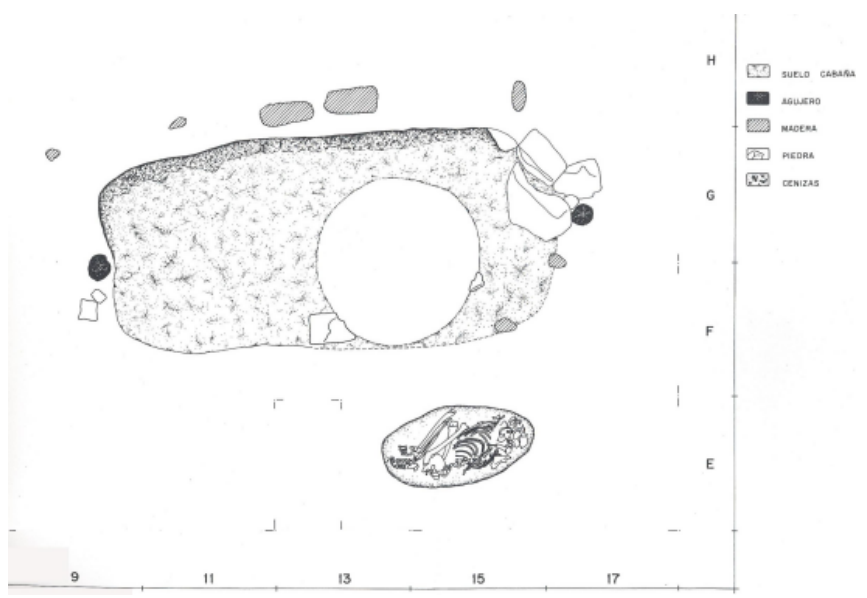

Fig. 3: Plano de una cabaña semiexcavada de los Tolmos (Caracena, Soria) (a partir de Jimeno y Fernández Moreno, 1991; fig. 7).

barro quemado y calcinado con improntas de ramajes- el suelo de tierra apisonada y los manteados de barro que recubrirían la estructura aérea de dos cabañas $^{14}$, sus correspondientes hogares en el exterior de las mismas, así como la inhumación de una mujer (Jimeno y Fernández Moreno, 1991: 1518).

Si los restos de las mencionadas cabañas pudieran ser interpretados a la manera tradicional, como los vestigios subsistentes tras los procesos postdeposicionales, en cambio, reclama una justificación distinta lo observado en el Fondo 56-57 de la Fábrica de Ladrillos (Getafe, Madrid). Este hoyo ${ }^{15}$ (Fig. 4) contenía, además de un fragmento de cráneo humano, más de $10 \mathrm{~kg}$. de cerámica, pellas de barro, arcilla apisonada y cocida, dos fragmentos de molino de granito, abundante industria lítica, restos óseos de perro ${ }^{16}$, vacuno, ovicaprino, cerdo y lagomorfo (Blanco et al., 2007: 282).

Aunque para los investigadores se trataría de una zona del poblado no estrictamente doméstica dedicada al procesado de alimentos (Blanco et al., 2007: 45-47), podríamos ver este conjunto como el enterramiento de una cabaña, incluyendo todos los enseres domésticos.

\section{NuEVAS PERSPECTIVAS}

La atribución de significado a unos vestigios tan fragmentarios reclama, desde luego, un enfoque diferente al habitual, orientado hacia la comprensión de los ciclos de vida y muerte de los objetos y las estructuras. Desde la propia 
Antropología Económica empieza a hablarse de la vida de las cosas y, como nos recuerda Kopytoff (1986: 64), la separación taxativa entre personas y objetos es excepcional, antropológicamente hablando.

Parece bastante sintomático que los seres humanos, las cabañas donde habitaron y los instrumentos que utilizaron hayan tenido el mismo tratamiento, unas veces depositados con cierta estética (Pollard, 2001) y otras careciendo de ella. Aquellos hoyos con unos contenidos ordenados, como la propia inhumación de Carrelasvegas, han sido tildados de rituales, pero si en todos los hoyos mencionados hay un resultado coincidente, sería apropiado pensar que existió una ritualización de la esfera doméstica en la que cada parte

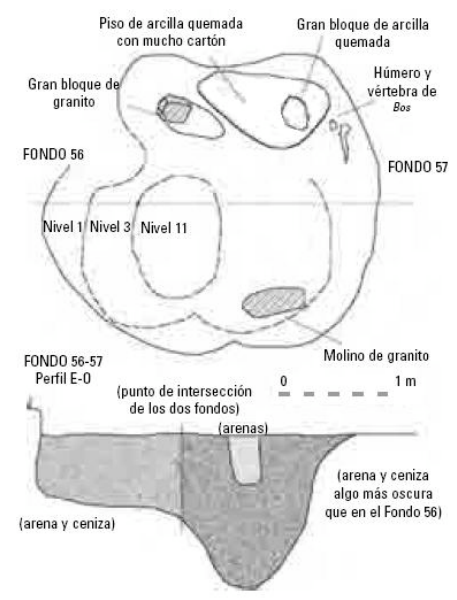

Fig. 4: Descripción sobre planta y alzado de materiales localizados en el F. 56-57 de la Fábrica de Ladrillos (Getafe, Madrid) (Blanco et al., 2007: 47; fig. 17).

carecería de sentido sin el todo al que perteneció (Bradley, 2005; Brück, 1999a). Por tanto, no estarían muy lejanos conceptualmente los distintos casos que se han recogido en este trabajo. Habría que investigar, entonces, sobre qué hechos pudieron ocurrir, por ejemplo, para que el colapso intencional -presumiblemente- de unas viviendas con objetos domésticos en su interior ${ }^{17}$, se asocie en muchas ocasiones con restos humanos y en último caso acaben formando parte del relleno de un hoyo ${ }^{18}$.

A tal efecto, en zonas donde los contextos arqueológicos son muy similares pero no más expresivos, como en Inglaterra o los Balcanes, se han realizado propuestas interesantes sobre la ligazón existente entre el ciclo vital de comunidades prehistóricas y sus asentamientos (Brück, 1999b: 158-60; Chapman, 2000: 68-70), observando que si los cambios en la vida de las per- 
sonas son asimilados por cada individuo de una forma diferente, también es cierto que la comunidad cultural en la que éste se inscribe tiene un peso decididamente mayor. Se vislumbra que no únicamente los ritos de paso, sino que éstos u otros sucesos tuvieron una importancia tal que implicaron la destrucción ritualizada de viviendas y su eliminación de la superficie para incluirla en un hoyo, con la posibilidad así de seleccionar qué objetos iban a formar parte del depósito subterráneo o de impedir acciones de rebusca.

Lamentablemente carecemos por el momento de un registro arqueológico que pueda darnos más información, por lo que serían necesarias modificaciones en la metodología de excavación para poder conocer con más exactitud contextos que de por sí no ofrecen información relevante, como siempre se ha pensado. La flotación del sedimento, el cribado de arenas, la referenciación topográfica de cada hallazgo, incluyendo todos los fragmentos de cerámica, óseos, líticos, así como el dibujo de materiales tan minusvalorados como pellas de barro, molinos -tanto si se encuentran fragmentados como completos- e incluso la toma del peso de estos materiales en caso de que no se vayan a conservar, y que integran la práctica habitual en excavaciones europeas $^{19}$, son entre nosotros desiderata.

Como contrapunto a esta nota de pesimismo, cabría plantearse como trabajos futuros, hasta qué punto este comportamiento pudo convertirse en regla a seguir; si existen relaciones espaciales de deposición de personas, cabañas y utensilios en los campos de hoyos; cómo se reflejan en la sociedad estas prácticas y sobre todo, hacia qué van encaminadas, es decir, qué perseguían los autores de estos depósitos mediante esta estrategia de ocultación deliberada tanto de sus muertos como de todo vestigio de su existencia.

\section{BIBLIOGRAFÍA}

ARANDA, G. y ESQUIVEL, J.A. (2007): "Poder y prestigio en las sociedades de la cultura de El Argar. El consumo comunal de bóvidos y ovicápridos en los rituales de enterramiento", Trabajos de Prehistoria 64. 2, págs. 95-118.

BELLIDO, A. (1996): Los campos de hoyos. Inicios de la economía agrícola en la submeseta Norte, [Serie Studia Archaeologica 85], Universidad de Valladolid, Valladolid.

BLANCO, J.F., BLASCO, M.C, RODRÍGUEZ, M.J. y CARRIÓN, E. (2007): "X. Inventario general", en Blasco, M.C. et al.: El Bronce Medio y Final en la región de Madrid. El poblado de la Fábrica de Ladrillos de Getafe [N monográfico Estudios de prehistoria y arqueología madrileñas 14-15], Museo de los Orígenes, Madrid, págs. 229-374. 
BLANCO, J.F., BLASCO, M.C, LIESAU, C., GARCÍA, J. y SANZ, M. (2007): "III. El análisis de las estructuras", en Blasco, M.C. et al.: El Bronce Medio y Final en la región de Madrid. El poblado de la Fábrica de Ladrillos de Getafe [ $\mathrm{N}^{\mathrm{o}}$ monográfico Estudios de prehistoria y arqueología madrileñas 14-15], Museo de los Orígenes, Madrid, págs. 29-70.

BLANTON, R.E. (1994): Houses and households. A comparative study, Plenum, Nueva York y Londres.

BLASCO BOSQUED, M. C. y LUCAS PELLICER, M. R. (2001): "Problemática del Bronce Final en la Meseta", SPAL 10, págs. 221-233.

BRADLEY, R. (2005): Ritual and domestic life in Prehistoric Europe, Routledge, Londres.

BRÜCK, J. (1999a): "Ritual and rationality. Some problems of interpretation in European archaeology", European Journal of Archaeology 2. 3, págs. 313-344.

BRÜCK, J. (1999b): "Houses, Lifecycles and Deposition on Middle Bronze Age Settlements in Southern England", Proceedings of the Prehistoric Society 65, págs. 145-166.

CASTRO MARTÍNEZ, P.V., MICÓ, R. y SANAHUJA, M.E. (1995): "Genealogía y cronología de la 'Cultura de Cogotas I' (El estilo cerámico y el grupo de Cogotas I en su contexto arqueológico)", Boletín del Seminario de Estudios de Arte y Arqueología 61, págs. 61-118.

CHAPMAN, J. (2000): "Pit-digging and structured seposition in the Neolithic and Copper Age", Proceedings of the Prehistoric Society 66, págs. $61-$ 87.

CHAPMAN, R. y RANDSBORG, K. (1981): "Approaches to the archaeology of death", en Chapman, R., Kinnes, I. y Randsborg, K.: The archaeology of death, Cambridge University Press, Cambridge, págs. 3-24.

DELIBES, G. (1978): "Una inhumación triple de facies Cogotas I en San Román de la Hornija (Valladolid)", Trabajos de Prehistoria 35, págs. 225250 .

DÍAZ-DEL-RÍO, P. (2001): La formación del paisaje agrario: Madrid en el III y II milenios BC [ $\mathrm{N}^{\circ}$ monográfico Arqueología, Paleontología y Etnografía 9], Comunidad de Madrid, Madrid.

ESPARZA, A. (1990): "Sobre el ritual funerario de Cogotas I", Boletín del Seminario de Estudios de Arte y Arqueología 56, págs. 105-143.

FERNANDEZ-POSSE, M. D. (1998): La investigación protohistórica en la Meseta y Galicia [Arqueología Prehistórica 1] Editorial Síntesis, Madrid. 
GARCÍA, J. y LIESAU, C. (2007): "VII. Los restos faunísticos", en Blasco, M.C. et al.: El Bronce Medio y Final en la región de Madrid. El poblado de la Fábrica de Ladrillos de Getafe $\mathrm{N}^{\mathrm{O}}$ monográfico Estudios de prehistoria y arqueología madrileñas 14-15], Museo de los Orígenes, Madrid, págs. 171-189.

GONZÁLEZ GONZÁLEZ, J.M. (1994): “Interpretación arqueológica de 'un campo de hoyos' en Forfoleda (Salamanca)", Zephyrus 43, págs. 309-314.

GONZÁLEZ-TABLAS, F.J. y FANO M.A. (1994): “El fenómeno de la muerte en Cogotas I: una propuesta metodológica”, Zephyrus 47, págs. 93 103.

HILL, J.D. (1995): Ritual and rubbish in the Iron Age of Wessex. A study on the formation of a specific archaeological record [BAR British Series 242], Oxford.

JIMÉNEZ-BROBEIL, S.A, OUMAUI, I.A, ESQUIVEL, J.A. (2004): "Actividad física según sexo en la cultura argárica. Una aproximación desde los restos humanos", Trabajos de Prehistoria 61. 2, págs. 141-153.

JIMENO, A. y FERNÁNDEZ MORENO, J.J. (1991): Los Tolmos de Caracena (Soria) (Campañas 1981 y 1982). Aportación al Bronce Medio de la Meseta, Excavaciones Arqueológicas en España 161.

KOPYTOFF, I. (1986): "The cultural biography of things: commoditization as process", en Appadurai, A. (ed.): The social life of things. Commodities in cultural perspective, Cambridge University Press, Cambridge, págs. 64-91.

LULL, V. (1997-1998): "El Argar: la muerte en casa”, Anales de Prehistoria y Arqueología 13-14, págs. 65-80.

LULL, V., MICÓ, R. y RISCH, R. (2004): “Las relaciones de propiedad en la sociedad argárica. Una aproximación a través del análisis de las tumbas de individuos infantiles", Mainake 26, págs. 233-272.

MARTÍN CARBAJO, M.A., MISIEGO TEJEDA, J.C., PÉREZ RODRÍGUEZ, F.J., FÉRNANDEZ GIMÉNEZ, J.M., SANZ GARCÍA, F.J., MARCOS CONTRERAS, G.J. (1993): “Documento funerario del Bronce Medio en la submeseta Norte: 'Carrelasvegas' (Santillana de Campos, Palencia)", Boletín del Seminario de Estudios de Arte y Arqueología 59, págs. 69-88.

MARTÍN BENITO, J.I y JIMÉNEZ, M.C. (1988-9): “En torno a una estructura constructiva en un campo de hoyos de la Edad del Bronce de la Meseta española (Forfoleda, Salamanca)", Zephyrus 41-42, págs. 263-281.

MORÁN, C. (1924): Excavaciones arqueológicas en el cerro del Berrueco $(\mathrm{Me}$ dinilla, Ávila, El Tejado y Puente de Congosto, Salamanca) [Memorias de la Junta Superior de Excavaciones y Antigüedades 65], Madrid.

POLLARD, J. (2001): “The aesthetics of depositional practice", World 
Archaeology 33. 2, págs. 315-333.

SAHLINS, M. (1979): "Hombre pobre, hombre rico, gran hombre, jefe: tipos políticos en Melanesia y Polinesia", en Llobera, J.R. (ed.): Antropologia politica, Ediciones Anagrama, Barcelona, págs. 267-288.

SANZ GARCÍA, FJ., MARCOS CONTRERAS, G.J., MARTÍN CARBAJO, M.A., MISIEGO TEJEDA, J.C., PÉREZ RODRÍGUEZ, F.J. (1994): “'La Aceña' (Huerta, Salamanca). Un campo de hoyos de Cogotas I en la Vega del Tormes”, Numantia: Arqueología en Castilla y León 1991/1992 5, págs. 73-86.

SIRET, E. y SIRET, L. (1890): Las primeras edades del metal en el sudeste de España. Imp. Henrich y Cía., Barcelona [citados por la ed. facsímil de 2006, Dirección General de Cultura de Murcia, Murcia, 2006].

STEVANOVIĆ, M. (1997): "The age of clay: The social dynamics of house destruction", Journal of Anthropological Archaeology 16, págs. 334-395.

STRATO (1991): Informe de la excavación arqueológica en el yacimiento de 'Carrelasvegas' (Santillana de Campos, Palencia), depositado en el Servicio Territorial de Cultura de la Junta de Castilla y León, Palencia, Informe inédito.

UCKO, P. J. (1969): "Ethnography and archaeological interpretation of funerary remains", World Archaeology 1. 2, págs. 262-280

\section{NOTAS}

* Beneficiaria de la Ayuda para la Formación de Personal Investigador (FPI) de la Junta de Castilla y León. Este trabajo ha sido parcialmente realizado en el marco del proyecto "Nuevos hallazgos y nuevas perspectivas en el estudio de los restos humanos de Cogotas I" (HAR-2009-10105/HIST), cuyo IP es el Dr. Ángel Esparza.

${ }^{1}$ En la Península Ibérica pueden ser reconocidos como tales los casos de Los Millares, El Argar (ambas sitas en Almería) (Siret, E. y Siret, L., 1890), El Berrueco (Salamanca) (Morán, 1924), etc.

${ }^{2}$ Sin lugar a dudas, constituye el grupo arqueológico de la Prehistoria Reciente peninsular trabajado con más profundidad y mayor amplitud de enfoques teórico-metodológicos, ejemplificando una verdadera historia de la investigación. Así mismo, para una revisión de los diferentes paradigmas teóricos que han imperado en el estudio específico de las manifestaciones funerarias, véase Lull (1997-8).

${ }^{3}$ Pueden consultarse algunas publicaciones que han tratado la sociedad argárica desde la antropología física, como Jiménez-Brobeil, Oumaui y Esquivel (2004) o Lull, Micó y Risch (2004); o desde las ofrendas cárnicas (Aranda y Esquivel, 2007).

${ }^{4}$ El Bronce Medio y Tardío de la submeseta norte y áreas limítrofes como gran parte de la 
región madrileña, manchega y extremeña se corresponde con la entidad arqueológica denominada Cogotas I. Su duración cronológica ha sido ajustada entre 1700-1000 calAC gracias al radiocarbono, y sin embargo, su seriación ha sido elaborada a partir de la vajilla cerámica (Castro Martínez, Micó y Sanahuja, 1995). Véase Blasco y Lucas (2001) para una síntesis de los rasgos culturales de Cogotas I.

${ }^{5}$ A saber: fue la primera tumba de Cogotas I fechada mediante radiocarbono; se localizaron tres individuos y unos ricos materiales que les acompañaban en la misma subestructura, tales como cerámicas profusamente ornamentadas y fracturadas, una fíbula broncínea de codo tipo 'Ría de Huelva', un espiraliforme y un lingotillo de este mismo material (Delibes, 1978).

${ }^{6}$ Sin embargo, se han generado largas polémicas, tanto en nuestro entorno peninsular como a nivel europeo, acerca de la función primaria (Bellido, 1996: 9-12) cuando su ciclo vital es mucho más largo y rico, y por tanto ofrece más información (Chapman, 2000: 64).

${ }^{7}$ Resulta sumamente habitual encontrar colmatando estos manchones cenicientos pellas de barro o adobes, recipientes cerámicos fragmentados, restos óseos de animales - pero también humanos-, molinos barquiformes completos o fracturados fabricados en rocas locales o alóctonas -cuya procedencia supone, en muchas ocasiones, recorrer decenas de kilómetros-, útiles líticos, óseos y metálicos, etc. En las publicaciones se les suele caracterizar de este modo, aunque habrá ocasión de debatir la función de vertederos que se les ha asignado a priori.

${ }^{8}$ No puede afirmarse con rotundidad que cada hoyo que contiene restos humanos fuera excavado exprofeso, puesto que en bastantes ocasiones los inhumados fueron colocados en hoyos semicolmatados, como apunta Díaz-del-Río (2001: 149 y 152) para la región madrileña.

${ }^{9}$ Este autor, además de realizar una compilación de los enterramientos asociados a cerámicas cogotenses, se planteaba cuestiones en torno a la diferenciación sexual, la posición de los inhumados, los espacios de enterramiento, o las consideraciones sociales que pudieron condicionar aquel trato a ciertos individuos de este grupo arqueológico (Esparza, 1990: 125137)

${ }^{10}$ El cuerpo estaba colocado decúbito prono, con las extremidades replegadas contra el tronco, orientado en dirección W-E en un hoyo cuya boca era circular, de $75 \mathrm{~cm}$. de diámetro, $130 \mathrm{~cm}$. de diámetro en la zona de mayor desarrollo, $125 \mathrm{~cm}$. de profundidad y sección troncocónica (Martín Carbajo et al., 1993: 78). Además, habría que destacar las diferencias de cota entre el inhumado (entre 76 y $89 \mathrm{~cm}$. de profundidad) y el posible ajuar (entre 90 y 95 cm. de profundidad) (Strato, 1991: planos 7 y 8).

${ }^{11}$ Casi sin paralelos en este yacimiento, pues tan sólo otro hoyo tenía unas dimensiones similares, también estaba estratificado, con un nivel negro de base y dos recipientes cerámicos casi completos (Strato, 1991: 27).

${ }^{12}$ En este caso, no se hace referencia a las actividades agrícolas, que sí han podido alterar sustancialmente el registro, sino a las acciones llevadas a cabo por las propias comunidades cogotenses para eliminar de forma deliberada todo rastro de la existencia de un antiguo poblado (Fernández-Posse, 1998: 241). 
${ }^{13}$ Esta condición no expresa la durabilidad del poblado o de la vivienda, ya que en otras regiones se ha comprobado que las chozas de ramas recubiertas de barro podían estar en pie con los pertinentes arreglos cerca de 20 años.

${ }^{14}$ Se documentó un ligero rebaje en el suelo para evitar la pendiente, cubierto por una capa de barro para evitar filtraciones, suelos de tierra batida y dos hoyos de poste en sendos lados de la estructura (Jimeno y Fernández Moreno, 1991:17).

${ }^{15}$ Sus medidas eran las siguientes: para el hoyo F.56, boca circular de $260 \mathrm{~cm}$. de diámetro, base plana de $110 \mathrm{~cm}$., profundidad a $60 \mathrm{~cm}$. y 612 l. de capacidad. El hoyo F. 57 presentaba mayor profundidad, hasta $125 \mathrm{~cm}$. y una capacidad de 911 l. El relleno de ambos era homogéneo, de arenas oscuras.

${ }^{16}$ Interpretado como la piel de un perro desollado (Liesau y García, 2007: 178).

${ }^{17}$ Stevanović (1997) ha hecho evidente la intencionalidad de los incendios que colapsaron algunas viviendas de ciertas áreas de poblados neolíticos y calcolíticos en los Balcanes. Acciones como estas pudieron haberse realizado en contextos como el nuestro, por lo que no podemos descartarlas sin tenerlas, siquiera, en consideración.

${ }^{18}$ A tal efecto, valdría recordar que las construcciones domésticas suelen estar íntimamente ligadas a sus moradores, siendo potentes medios de reproducción social y por tanto, de comunicación (Blanton, 1994: 10).

${ }^{19}$ Véase Stevanović (1997) como referencia de una excavación minuciosamente planificada, con unas preguntas previas a las que se intenta responder y que son continuamente cuestionadas en el transcurso de las investigaciones. 